\title{
TEMPERATURA DA ÁGUA EM BEBEDOUROS UTILIZADOS EM INSTALAÇÕES PARA AVES DE POSTURA
}

\author{
ELCIO S. KLOSOWSKI ${ }^{1}$, ALESSANDRO T. CAMPOS ${ }^{1}$, ELIANE GASPARINO ${ }^{2}$, \\ ALOÍSO T. DE CAMPOS ${ }^{3}$, DANIELE F. AMARAL ${ }^{4}$
}

\begin{abstract}
RESUMO: A temperatura da água exerce influência sobre o seu consumo pelas aves e sobre a produtividade das mesmas. Entretanto, existe carência de informações comparando a temperatura da água entre os bebedouros mais comumente empregados em aviários de postura no Brasil. Neste trabalho, avaliou-se a variação da temperatura da água para dois tipos de bebedouro: "nipple" e calha. O experimento foi conduzido em uma instalação comercial de postura, localizada na região Oeste do Paraná. Para a determinação da temperatura da água, das 8 às $18 \mathrm{~h}$, foram instalados termômetros de mercúrio com o bulbo inserido no interior da água em bebedouros tipo "nipple" e calha, em dois galpões idênticos. Foi estimado o ITGU do ambiente a partir de dados obtidos de termômetros de globo negro instalados em local próximo ao da coleta de temperatura da água, na região central dos galpões. Os maiores valores de temperatura da água foram observados no sistema "nipple", que atingiu $31^{\circ} \mathrm{C}$ às $16 \mathrm{~h}$, em média, enquanto no sistema calha atingiu $26,4^{\circ} \mathrm{C}$. Observou-se a existência de relação entre a temperatura da água e os valores de ITGU, sendo o maior coeficiente de correlação encontrado para o sistema "nipple", de $\mathrm{R}^{2}=0,9040$, enquanto para o sistema de calha foi de $\mathrm{R}^{2}=0,8424$. Desconsiderando $\mathrm{o}$ aspecto sanitário, para as condições em que o trabalho foi desenvolvido, pode-se concluir que o melhor sistema, em termos de temperatura da água de bebida, foi o tipo calha.
\end{abstract}

PALAVRAS-CHAVE: sistemas de fornecimento de água, desempenho térmico, aves de postura.

\section{WATER TEMPERATURE IN WATERERS USED IN LAYNG HENS HOUSING}

SUMMARY: Animal's water consumption and productivity are influenced by the drinking water temperature. However, there is a lack of information comparing water temperature in nipple and continuous drinker systems, commonly employed in Brazilian layer hens housing. In this research, drinking water temperature variation was evaluated considering two waterier systems: nipple and continuous. The trial was conduced in a laying hens commercial housing, located in the West region of Paraná State, Brazil. For the water temperature recording, thermometers were placed inside the water in the nipple and the continuous drinker systems, in two similar buildings, from 8:00 AM to 6:00 PM. The BGHI (black globe humidity index) was estimated using the obtained data from black globe thermometers placed near the place where water temperature was recorded, in the central area of the building. The highest water temperature values were observed in the nipple system, that reached $31{ }^{\circ} \mathrm{C}$ at 4:00 PM (average values), while in the continuous system it reached $26.4^{\circ} \mathrm{C}$. A relation between water temperature and environmental BGHI values was calculated. The highest correlation coefficient was found for the nipple system. Without considering the sanitary aspect for the conditions in which the work was developed, it can be concluded that the best system is the continuous waterier, in terms of drinking water temperature.

KEYWORDS: watering systems, thermal perfomance, layers.

\footnotetext{
${ }^{1}$ Prof. Adjunto, Centro de Ciências Agrárias, GPEA - Grupo de Pesquisas em Ambiência do Oeste do Paraná, Universidade Estadual do Oeste do Paraná, Rua Pernambuco, 1777, Marechal Cândido Rondon - PR, e-mail: elciosk@oel.br

${ }^{2}$ Profa. Adjunta, Departamento de Zootecnia, GPEA, UEM, Maringá - PR.

${ }^{3}$ Pesquisador, Doutor, GPEA, Embrapa - Gado de Leite, Juiz de Fora - MG.

${ }^{4}$ Zootecnista, UNIOESTE, Estagiária do GPEA, Marechal Cândido Rondon - PR.

Recebido pelo Conselho Editorial em: 28-8-2003

Aprovado pelo Conselho Editorial em: 19-7-2004
} 


\section{INTRODUÇÃO}

A água é o nutriente requerido em maior quantidade para as aves e, segundo HARRIS JUNIOR et al. (1975), deveria ser considerado o nutriente essencial mais importante. É a substância mais abundante nos sistemas vivos, e a porcentagem de água do corpo depende de fatores como a espécie, a quantidade de gordura e a idade do animal. Para galinhas, a quantidade de água corpórea em porcentagem do peso total de animais adultos corresponde a 53\% (PIZAURO JÚNIOR, 1996).

De acordo com SILVA \& SEVEGNANI (2001), apenas parte da energia alimentar ingerida pelas aves é convertida na produção de ovos. O restante é empregado na manutenção fisiológica, nos mecanismos de homeotermia, ou perdido para o ambiente na forma de calor, por meio dos processos físicos de transferência de calor - condução, convecção, radiação e, também, evaporação. A quantidade de água ingerida pelas aves aumenta com a elevação da temperatura ambiente, sendo o consumo, em situação de estresse calórico, limitante para a taxa de crescimento e sobrevivência. NORTH (1984) citado por BAIÃO (1995), estudando 100 aves Leghorn com peso de $1,8 \mathrm{~kg}$, obteve aumento de consumo de água de 17,8 para $40,9 \mathrm{~kg}$ quando a temperatura ambiente passou de 15,6 para $37,8^{\circ} \mathrm{C}$, num período de 24 horas. A qualidade e a temperatura da água são pontos importantes de manejo na condição de estresse, sendo o aumento do seu consumo fundamental nos mecanismos envolvidos na termorregulação. Para promover redução na temperatura corporal, a temperatura da água deve estar em torno de $20^{\circ} \mathrm{C}$ (MACARI \& FURLAN, 2001).

Pesquisas demonstram que o desempenho das aves pode ser afetado pelo tipo de sistema de fornecimento de água. MACARI (1996) relata um estudo realizado nos Estados Unidos, no qual se constatou que a postura de poedeiras foi diminuída com a alteração do sistema, de calha para o tipo "nipple" em gaiolas.

GERNAT \& ADAMS (1992), em experimentos realizados no Kansas, relacionando o número de aves por "nipple" (razões de 2:1 a 14:1 aves por "nipple"), verificaram que, nos tratamentos com menos aves por "nipple", houve consumo significativamente maior de água e ração; entretanto, não houve variação da idade de maturidade sexual, da produção de ovos, mortalidade e do tamanho dos ovos.

Há disponível no mercado diversos modelos e capacidades de bebedouros para poedeiras criadas em gaiolas, confeccionados em diferentes materiais, destacando-se o tipo "nipple" e o tipo calha. O "nipple" possui válvula de metal que, quando acionada pela ave por meio do bico, libera água automaticamente por pressão, não requerendo higienização constante ou abastecimento. É indicado para todas as fases, porém com custo de implantação mais elevado. $O$ bebedouro calha pode ser com válvula ou bóia, automático, confeccionado em metal com custo relativamente baixo, porém com maior possibilidade de contaminação da água. Há também o tipo calha com água corrente, que oferece água mais fresca, porém exige maior fluxo de água no sistema (MAZZUCO et al., 1997). Segundo TEIXEIRA (1997), no tipo calha, há indicação de um centímetro por ave e, para o tipo "nipple", é indicado um bico para dez a quinze aves.

GERNAT \& ADAMS (1990) afirmaram que selecionar um sistema de bebedouro para aves de postura pode ser difícil, devido às variáveis que podem afetar a eficiência de determinado sistema, considerando a carência de dados de pesquisa publicados caracterizando o desempenho desses sistemas.

O objetivo do presente trabalho foi avaliar a temperatura da água para bebedouros tipo calha e "nipple", em galpão de poedeiras, em período de verão. 


\section{MATERIAL E MÉTODOS}

O trabalho foi desenvolvido no período de 14 de dezembro de 2001 a 15 de janeiro de 2002, em granja comercial de poedeiras localizada no município de Marechal Cândido Rondon, Estado do Paraná, tendo coordenadas geográficas de latitude $24^{\circ} 33^{\prime} 40^{\prime}$ ' S, longitude $54^{\circ} 04^{\prime} 12^{\prime}$ W W altitude média de $420 \mathrm{~m}$. De acordo com a classificação proposta por Köeppen, o clima é subtropical úmido, com precipitação média anual de $1.840 \mathrm{~mm}$ e temperatura média anual variando entre 14 e $28{ }^{\circ} \mathrm{C}$ (IAPAR, 1978).

Foram utilizados dois galpões convencionais idênticos, com estrutura de madeira, cobertos com telhas cerâmicas, com um metro de beiral, sem lanternim e pé-direito de $2,4 \mathrm{~m}$. Com 33,0 m de comprimento e 3,5 m de largura, os aviários possuíam quatro linhas com 100 gaiolas cada. A gaiola apresentava dimensões de 0,42 $\mathrm{m}$ de comprimento, $0,30 \mathrm{~m}$ de largura e $0,40 \mathrm{~m}$ de altura, abrigando três aves, perfazendo um total de 1.188 aves por galpão.

Os tratamentos foram constituídos pelo bebedouro tipo "nipple" (galpão 1) e pelo bebedouro tipo calha (galpão 2). Na região central dos galpões, para avaliação da temperatura da água, foi instalado em cada bebedouro um termômetro de mercúrio com o bulbo em contato direto com a água de bebida. O posicionamento do termômetro no interior da tubulação do bebedouro tipo "nipple" pode ser observado na Figura 1. Para a avaliação do ambiente térmico, foi estimado o Índice de Temperatura do Globo e Umidade (ITGU) a partir dos dados médios coletados em termômetros de globo negro instalados dentro de duas gaiolas sem aves, na região central do galpão, próximo ao local onde foram coletadas as temperaturas da água em cada galpão. A temperatura do ar e a de bulbo úmido foi determinada por meio de psicrômetro no interior de cada galpão.
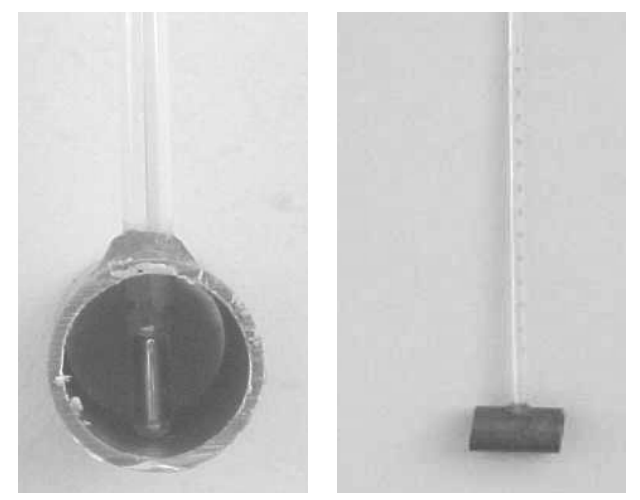

FIGURA 1. Detalhe da instalação do termômetro na tubulação do bebedouro tipo "nipple".

Para a determinação das relações psicrométricas, assim como para a determinação da amplitude térmica do ar externo, foram instalados um psicrômetro e um termômetro de máxima e mínima, do tipo capela, em abrigo meteorológico localizado próximo aos galpões.

As coletas de dados foram realizadas em intervalos regulares de duas horas, no período compreendido entre as 8 e $18 \mathrm{~h}$.

Para a determinação do ITGU, foi utilizada a equação proposta por BUFFINGTON et al. (1981):

ITGU $=t_{\mathrm{g}}+0,36 \mathrm{t}_{\mathrm{po}}+41,5$

em que,

$\mathrm{t}_{\mathrm{g}}$ - temperatura de globo negro, ${ }^{\circ} \mathrm{C}$;

$\mathrm{t}_{\mathrm{po}}$ - temperatura do ponto de orvalho, ${ }^{\circ} \mathrm{C}$. 
Para as análises estatísticas, foi utilizado o programa computacional SAEG (1984). Os valores médios de ITGU obtidos nos dois galpões foram comparados pelo teste $\mathrm{F}$, a $5 \%$ de probabilidade. Comparou-se também a temperatura da água para os dois sistemas, pelo teste de Tukey, no mesmo nível de significância, para seis horários e, visando a estabelecer uma relação entre valores médios de temperatura da água e ITGU, foi estimada a correlação entre esses dois parâmetros para os tipos de bebedouros estudados.

\section{RESULTADOS E DISCUSSÃO}

No período de realização do experimento, foram registrados os seguintes valores para os elementos meteorológicos: temperatura média diária do ar de $27,5^{\circ} \mathrm{C}$; temperatura máxima média de $32,0{ }^{\circ} \mathrm{C}$; temperatura mínima média de $18,4^{\circ} \mathrm{C}$; temperatura máxima absoluta de $36,6^{\circ} \mathrm{C}$; temperatura mínima absoluta de $13,0^{\circ} \mathrm{C}$; umidade relativa média diária de $68,3 \%$; umidade relativa máxima absoluta de $92 \%$ e umidade relativa mínima absoluta de $37 \%$.

O valor médio diário de ITGU, para o galpão 1, foi de 77,4, enquanto para o galpão 2 foi de 77,2 , não tendo sido observada diferença estatística, pelo teste $\mathrm{F}$, a $5 \%$ de probabilidade, entre os galpões.

Na Tabela 1, exceto para as $8 \mathrm{~h}$, os valores médios de temperatura da água obtidos para o bebedouro tipo "nipple" foram sempre superiores aos obtidos no bebedouro tipo calha, diferindo significativamente, pelo teste de Tukey, a 5\% de probabilidade. Esse comportamento pode ser melhor observado na Figura 2. Para as condições de Assis - SP, SILVA (1998) avaliou bebedouro tipo calha em aviário de postura, verificando que a temperatura média da água permaneceu acima do valor máximo recomendado $\left(24^{\circ} \mathrm{C}\right)$ durante $70 \%$ do período estudado. Entre 8 e $20 \mathrm{~h}$, o autor obteve temperatura da água ligeiramente inferior na região central do galpão quando comparada com as extremidades do mesmo, ocorrendo uma tendência inversa nas observações das 12 e $16 \mathrm{~h}$, em que os maiores valores ocorreram na região central do galpão. De forma semelhante ao presente trabalho, SILVA (1998) também observou que a temperatura média da água foi inferior a $24^{\circ} \mathrm{C}$ somente às $8 \mathrm{~h}$.

TABELA 1. Temperatura média da água para os dois tipos de bebedouros no período compreendido entre $8 \mathrm{~h}$ e $18 \mathrm{~h}$ para cada intervalo de duas horas*.

\begin{tabular}{lcccccc}
\hline \multirow{2}{*}{ Tratamentos } & \multicolumn{6}{c}{ Temperatura Média da Água $\left({ }^{\circ} \mathrm{C}\right)$} \\
\cline { 2 - 7 } & $8 \mathrm{~h}$ & $10 \mathrm{~h}$ & $12 \mathrm{~h}$ & $14 \mathrm{~h}$ & $16 \mathrm{~h}$ & $18 \mathrm{~h}$ \\
\hline Galpão 1 (Bebedouro "Nipple") & $21,7 \mathrm{a}$ & $25,9 \mathrm{a}$ & $28,8 \mathrm{a}$ & $30,5 \mathrm{a}$ & $31,0 \mathrm{a}$ & $29,6 \mathrm{a}$ \\
Galpão 2 (Bebedouro Calha) & $21,7 \mathrm{a}$ & $24,1 \mathrm{~b}$ & $25,3 \mathrm{~b}$ & $25,8 \mathrm{~b}$ & $26,4 \mathrm{~b}$ & $25,5 \mathrm{~b}$ \\
\hline
\end{tabular}

*Médias seguidas da mesma letra, na coluna, não diferem significativamente, pelo teste de Tukey, a 5\% de probabilidade.

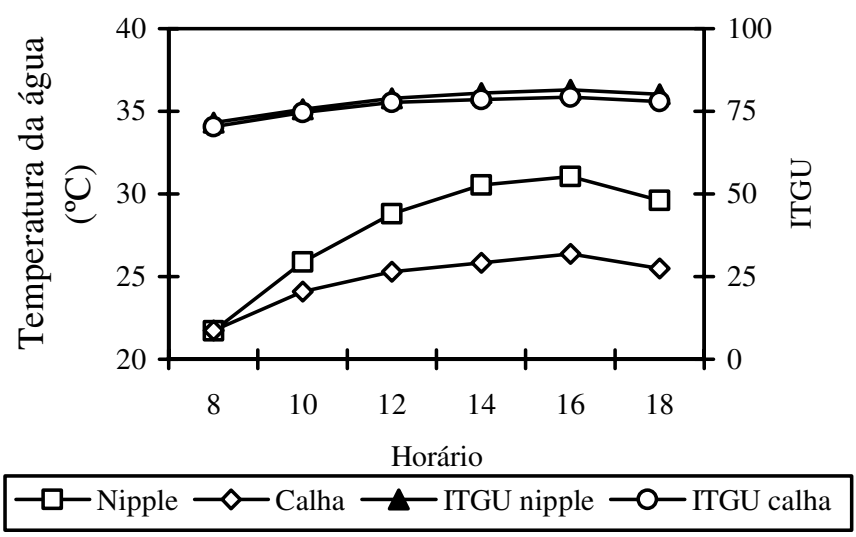

FIGURA 2. Variação da temperatura da água e do ITGU, para os sistemas "nipple" e calha, no período entre $8 \mathrm{~h}$ e $18 \mathrm{~h}$. 
Animais devem ingerir quantidades adequadas de água em intervalos regulares, especialmente em ambientes quentes (CURTIS, 1983). O autor relata que aves rejeitam a água de bebida quando sua temperatura eleva-se acima da ambiente. É fato que a temperatura da água interfere no consumo da ave, que ingere menos quando a temperatura da água aumenta. A resposta desencadeada no nervo lingual da ave inicia-se quando a temperatura da água está na faixa de $24^{\circ} \mathrm{C}$. Quando a temperatura da água atinge $36^{\circ} \mathrm{C}$, há grande aumento da atividade nervosa, dez vezes maior do que a $24^{\circ} \mathrm{C}$. Esse efeito neurofisiológico mostra que a temperatura da água acima de $24{ }^{\circ} \mathrm{C}$ pode ser percebida pela ave, sendo transmitida por informação térmica emitida pelo sistema nervoso central e, caso haja possibilidade de escolha, a ave optará por água com temperatura inferior a $24^{\circ} \mathrm{C}$ (MACARI, 1996).

No período estudado, os valores médios de temperatura da água excederam $24^{\circ} \mathrm{C}$, para ambos os sistemas, a partir das $10 \mathrm{~h}$. No bebedouro tipo "nipple", a partir das $14 \mathrm{~h}$, a temperatura da água atingiu $30,0^{\circ} \mathrm{C}$, tendo sido observado o valor máximo às $16 \mathrm{~h}\left(31^{\circ} \mathrm{C}\right)$, decaindo ligeiramente às $18 \mathrm{~h}$ $\left(29,6^{\circ} \mathrm{C}\right)$. A situação se agrava considerando a permanência desses altos valores de temperatura, em torno de $30^{\circ} \mathrm{C}$, até as $18 \mathrm{~h}$. Esse comportamento se explica, provavelmente, devido ao fato de a água apresentar inércia térmica muito maior do que a do ar, mantendo-se, dessa forma, em valores relativamente altos até o final do dia. Importante ressaltar que os valores descritos se tratam de médias. Em determinados períodos do experimento, a temperatura da água atingiu valores ainda maiores; no oitavo dia, às $16 \mathrm{~h}$, por exemplo, constatou-se, no sistema "nipple", valor de $36,0^{\circ} \mathrm{C}$ e, de acordo com as considerações de SILVA \& SEVEGNANI (2001), isso pode ter provocado alta atividade nervosa nos animais abastecidos por aquele tipo de bebedouro, enquanto para o sistema calha, no mesmo dia e horário, a temperatura foi de $27,2^{\circ} \mathrm{C}$. Complementando, ABREU \& ABREU (2000) afirmam que pouco se sabe sobre a temperatura ótima de ingestão de água; entretanto, os autores recomendam que a temperatura da água não deva ser superior a $24,0^{\circ} \mathrm{C}$ e que deva ser inferior à temperatura corporal.

Observou-se, neste trabalho, que, para vários períodos, a temperatura da água no interior do "nipple" se aproxima da temperatura corporal das aves, cuja amplitude varia de 40,6 a $43,0{ }^{\circ} \mathrm{C}$ para aves adultas, com média de $41,8^{\circ} \mathrm{C}$ (SILVA, 2000). Para ABREU \& ABREU (2000), a eficiência em eliminar calor corporal será tanto maior quanto maior for o gradiente de temperatura entre a água e o animal, ou seja, quanto menor a temperatura da água, maior será sua potencialidade em contribuir para reduzir a temperatura corporal do animal que a ingere.

Os valores médios diários de temperatura da água para os bebedouros "nipple" e calha foram de $27,9^{\circ} \mathrm{C}$ e de $24,8^{\circ} \mathrm{C}$, respectivamente. Entretanto, notaram-se diferenças nos valores médios de temperatura da água de 1,$8 ; 3,5 ; 4,7 ; 4,6$ e $4,1^{\circ} \mathrm{C}$ entre os dois tipos de bebedouros, para as $10 \mathrm{~h}, 12 \mathrm{~h}$, $14 \mathrm{~h}, 16 \mathrm{~h}$ e $18 \mathrm{~h}$ (Tabela 1), respectivamente. Pelos resultados apresentados, evidencia-se que a temperatura da água foi mais adequada no sistema calha, quando comparado ao "nipple" para as condições do estudo, concluindo-se, a princípio, ser o primeiro mais indicado. Entretanto, não se deve deixar de atentar aos aspectos sanitários. MAZZUCO et al. (1997) consideram que o bebedouro tipo calha apresenta maior possibilidade de contaminação.

Encontraram-se na literatura referências em que o bebedouro tipo calha oferece água mais fresca; entretanto, não se deparou com valores referentes às temperaturas da água para esse sistema quando comparado ao bebedouro tipo "nipple". ROUSH \& BOGGAN (1987), por exemplo, avaliaram o desempenho de poedeiras criadas em gaiolas abastecidas por bebedouro tipo "nipple" comparado a vários modelos de bebedouros tipo taça. As aves abastecidas pelos modelos de sistemas tipo taça tiveram produção diária de ovos entre 5,5 e 8,8\% maior. Os piores resultados em termos de conversão alimentar, peso corporal e mortalidade foram obtidos para os animais abastecidos pelo sistema "nipple". Contudo, os autores não apresentaram dados de temperatura da água. Já RAMOS et al. (1990), comparando bebedouros "nipple" com um sistema semi-automático do tipo taça, encontraram piores resultados de consumo alimentar, peso do ovo, idade de maturidade sexual e produção diária de 
ovos. Entretanto, os dados de mortalidade e peso corporal dos animais foram favoráveis para o sistema "nipple". Novamente não foram apresentados os valores de temperatura.

Foi constatado que a temperatura da água sofreu influência da temperatura do ambiente por meio do ITGU. Na Figura 3, pode ser observada a relação entre os valores de ITGU e da temperatura da água nos dois tipos de bebedouros. Como se depara nessa Figura, a curva que representou a variação da temperatura da água em função dos valores de ITGU para o bebedouro tipo "nipple", apresentou maior coeficiente angular (FIGURA 3A); portanto, para cada acréscimo observado do ITGU, verificaram-se maiores elevações na temperatura da água no interior do bebedouro tipo "nipple". A temperatura média diária da água no sistema "nipple" foi de $27,9{ }^{\circ} \mathrm{C}$, ou seja, $0,4{ }^{\circ} \mathrm{C}$ acima da temperatura média do ar ambiente, que foi de $27,5^{\circ} \mathrm{C}$ no período. Já no sistema calha, a temperatura média diária da água foi de $24,8^{\circ} \mathrm{C}$, portanto $2,7^{\circ} \mathrm{C}$ abaixo da temperatura média do ar ambiente. Como a água é contida no interior da tubulação, a perda de calor dessa para o ar, por condução, é reduzida, sendo a perda por convecção impossível nesse sistema. Já no bebedouro tipo calha, existe uma vasta área de contato entre a água e o ar ambiente, que favorece as perdas de calor por condução, convecção e, principalmente, as perdas de calor na forma latente, por evaporação.

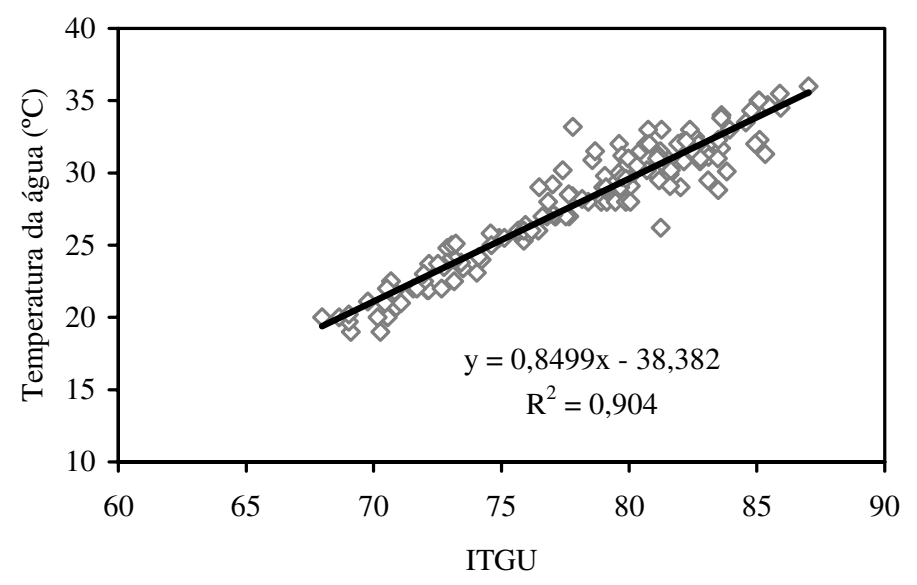

A - Galpão 1

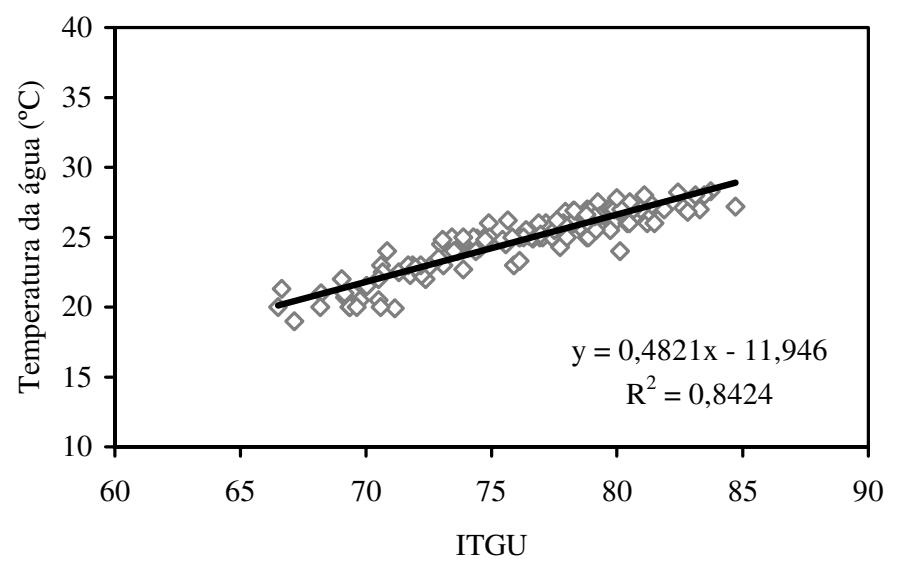

B - Galpão 2

FIGURA 3. Temperatura da água em função do ITGU para os bebedouros tipo: A - Galpão 1 ("nipple") e B - Galpão 2 (calha). 
A relação de dependência entre a temperatura da água e o ITGU fica mais evidenciada na Figura 3A (Galpão 1 - sistema "nipple"), em que a curva se ajustou com $\mathrm{R}^{2}$ de 0,904 quando comparado ao ajuste observado para o bebedouro tipo calha, apresentado na Figura $3 B$, em que o valor de $R^{2}$ foi de 0,8424 .

\section{CONCLUSÕES}

No período estudado, a temperatura média da água foi maior para o bebedouro tipo "nipple".

As maiores diferenças nos valores de temperatura da água se verificam a partir das $14 \mathrm{~h}$, prolongando-se até às $18 \mathrm{~h}$.

Foi verificada relação entre a temperatura da água e o ITGU do ambiente, sendo a maior correlação observada para o bebedouro tipo "nipple".

Pelos resultados obtidos e desconsiderando-se os aspectos sanitários, o melhor sistema seria o tipo calha quando comparado com o "nipple".

\section{REFERÊNCIAS}

ABREU, V.M.N.; ABREU, P.G. Temperatura da água em bebedouros tipo calha. Concórdia: EMBRAPA-CNPSA, 2000. 3p. (Comunicado Técnico, 265).

BAIÃO, N.C. Efeitos da densidade populacional sobre o ambiente das instalações avícolas. In: SIMPÓSIO INTERNACIONAL DE AMBIÊNCIA E INSTALAÇÃO NA AVICULTURA INDUSTRIAL, 1., 1995, Campinas. Livro de textos... Campinas: FACTA, 1995. p.67-75.

BUFFINGTON, D.E.; COLLAZO-AROCHO, A.; CANTON, G.H.; PITT, D.; THATCHER, W.W.; COLLIER, R.J. Black-globe-humidity index (BGHI) as comfort equation for dairy cows. Transactions of the ASAE, St. Joseph, v.24, n.3, p.711-14, 1981.

CURTIS, S.E. Environmental management in animal agriculture. Ames: Iowa State University Press. 1983. 409 p.

GERNAT, A.G.; ADAMS, A.W. Effect of number and location of nipple wateres and cage shape on the performance of caged layers. Poultry Science, Champaign, v.69, n.12, p.2086-91, 1990.

GERNAT, A.G.; ADAMS, A.W. Effect of number of hens per nipple waterer on the performance of several strains of layers in cages. Poultry Science, Champaign, v.71, n.8, p.1292-5, 1992.

HARRIS JUNIOR, G.C.; NELSON, G.S.; SEAY, R.L.; DODGEN, W.H. Effects of drinking water temperature on broiler performance. Poultry Science, Champaign, v.54, n.3, p.775-9, 1975.

INSTITUTO AGRONÔMICO DO PARANÁ. Cartas climáticas básicas do Estado do Paraná. Londrina: IAPAR, 1978.

MACARI, M. Água na avicultura industrial. Jaboticabal: FUNEP, 1996. 128 p.

MACARI, M.; FURLAN, R.L. Ambiência na produção de aves em clima tropical. In: SILVA, I.J.O. (Ed.). Ambiência na produção de aves em clima tropical. Jaboticabal: SBEA, 2001, p.31-87.

MAZZUCO, H.; ROSA, P.S.; PAIVA, D.P.; JAENISCH, F.; MOY, J. Manejo e produção de poedeiras comerciais. Concórdia: EMBRAPA-CNPSA, 1997. 67p. (Documentos, 44).

PIZANRO JÚNIOR, J.M. A água nos processos biológicos. In: MACARI, M. Água na avicultura industrial. Jaboticabal: FUNEP, 1996. p.5-26. 
RAMOS, N.C.; GERNAT, A.G.; ADAMS, A.W. Effects of cage shape, age at housing, and types of rearing and layer wateres on the productivity of layers. Poultry Science, Champaign, v.69, s/n, p.21723, 1990.

ROUSH, W.B.; BOGGAN, G.D. Effect of watering devices on performance during pullet-rearing and cage-laying phases of Single Comb White Leghorn hens. Poultry Science. Champaign, v.66, s/n, p.1431-6, 1987.

SILVA, I.J.O. Desenvolvimento de modelos matemáticos para análise da influência das condições ambientais na produção de ovos. 1998. 140 f. Tese (Doutorado em Construções Rurais e Ambiência) Faculdade de Engenharia Agrícola, Universidade Estadual de Campinas, Campinas, 1998.

SILVA, I.J.O.; SEVEGNANI, K.B. Ambiência e instalações na avicultura de postura. In: SILVA, I.J.O. (ed.) Ambiência na produção de aves em clima tropical. Jaboticabal: SBEA, 2001. v.2. p.150214.

SILVA, R.G. Introdução à bioclimatologia animal. São Paulo: Nobel, 2000. 286 p.

SAEG - Sistema para Análises Estatísticas e Genéticas. Viçosa, MG: UFV/CPD, 1984. 94 p.

TEIXEIRA, V.H. Construções e ambiência: instalações para suínos e aves. Lavras: UFLA/FAEPE, 1997. 182 p. 